テルミット法による鉄ーフェライト混合粉の作製および磁気特性

平塚 信之, 遠田 博美, 藤田 実

小林 秀彦, 三田村 孝

埼玉大学工学部， $\mathbf{3} 338$ 浦和市下大久保 255.

\title{
Preparation of Mixtures of Irons and Ferrites by Thermite Method and Their Magnetic Properties
}

Nobuyuki Hiratsuka, Hiromi Toda, Minoru Fujita Hidehiko Kobayashi and Takashi Mitamura

Faculty of Engineering, Saitama University, 255 Shimo-ohkubo, Urawa 338.

Received July 22, 1992

Ferromagnetic composites which contained iron and iron zinc ferrite $\left(\mathrm{Zn}_{\mathrm{X}} \mathrm{Fe}_{3-\mathrm{x}} \mathrm{O}_{4}\right)$ were prepared by the Thermite method, and their crystal phases and magnetic properties were investigated. The mixtures of $\mathrm{Zn} / \alpha-\mathrm{Fe}_{2} \mathrm{O}_{3}$ molar ratio of $0.3-2.0$ were sintered between $400^{\circ} \mathrm{C}$ and $800^{\circ} \mathrm{C}$ for $1 \mathrm{hr}$ in argon gas, and then were quenched.

The samples that were sintered between $450^{\circ} \mathrm{C}$ and $500^{\circ} \mathrm{C}$ had a large amount of a spinel phase $\left(\mathrm{Zn}_{\mathrm{X}} \mathrm{Fe}_{3-\mathrm{X}} \mathrm{O}_{4}\right)$. When the samples were sintered between $550^{\circ} \mathrm{C}$ and $700^{\circ} \mathrm{C}$, the spinel phase was decreased by the thermal decomposition: non magnetic oxides, $\mathrm{FeO}$ and $\mathrm{ZnO}$ were formed. Iron powders were formed by the sintering at $800^{\circ} \mathrm{C}$ or above. The spinel phase was formed when $\mathrm{Zn} / \alpha-\mathrm{Fe}_{2} \mathrm{O}_{3}$ with molar ratio less than 1 was sintered at $500^{\circ} \mathrm{C}$ for $1 \mathrm{hr}$ in argon gas. The sample whose molar ratio of 0.35 had the magnetization of $85 \mathrm{emu} / \mathrm{g}$ and the coercive force of $0.11 \mathrm{kOe}$. The synthesized fine particles were sperical in shape and their diameters were in the range of 0.3 to $0.6 \mu \mathrm{m}$. The future work is to make ferromagnetic materials which coexist irons and spinel ferrites without non magnetic oxides.

1 はじめに

フェライトは高い電気抵抗率之優れた耐摩耗性を有 するが，飽和磁化值が小さい，一方，金属磁性材料は 飽和磁化值が大きい，したがって，フェライトと金属 磁性材料を複合すると両者の長所を兼ね備えた高飽和 磁化值および高抵抗率の材料になる可能性がある．上
述のような複合材料を作製する試みは杉本等により報

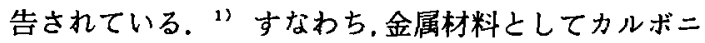
ル鉄粉を，そして酸化物材料として各種のスピネル型 フェライト粉末をそれぞれ混合し，2mmHgの減圧中で焼 成することにより，両者間の反応の進行が少ない烧結 体を得ることができた。その一例として，カルボニル 
鉄粉およびマグネタイトを重量比 $1: 3$ に混合し，900 で15分焼成して、飽和磁束密度が8780Gauss，抵抗率が $10^{-4} \Omega \cdot \mathrm{cm}$ の複合材料を作製した.これらの特性は飽和 磁束密度がフェライトよりあ大きく，かつ，抵抗动す 金属よりあ1析以上大きくなった。

またメカノフュージョン装置を使用し，センダスト 粒子のまわりにニッケル銅亜鈆フェライトをコーティ ングした。これを短時間焼結して複合粒子を作製する 試みる報告された。 ${ }^{2)} さ ら に F e 4 / / \mathrm{Fe}_{3} \mathrm{O}_{4}$ の多層化によ る複合磁性膜の報告もある. ${ }^{3 !}$

本研究は磁性金属および磁性酸化物が共存する複合 材料をテルミット法を応用して作製した。すなわち， $\alpha-\mathrm{Fe}_{2} \mathrm{O}_{3}$ とZnを組み合わせてアルゴンガス中で反饥さ せると， $\alpha-\mathrm{Fe}_{2} \mathrm{O}_{3}$ から酸素が離脱 $\mathrm{L}, \mathrm{Fe}$ が生成すると ともに，その反応により生じた酸化亜鈶と酸化鉄が化 合して鉄亜鈆フェライトを作製するすのである。これ らの合成法および磁気特性について報告する。

\section{2 実験方法}

出発原料には， $\alpha-\mathrm{Fe}_{2} 0_{3}$ 粉末（純度: $99.9 \%$, 平 均粒子径: $1 \mu \mathrm{m}$ ) とZn粉末 (純度: $99.9 \%$, 粒度: $-200 x \%$ シュ)を用いた．めのう乳鉢で所定モル比 $\left(\mathrm{Zn} / \mathrm{Fe}_{2} \mathrm{O}_{3}=\right.$ 0.3〜2)の粉末を十分混合した後、アルミナボートに充 填した．図1は反応装置の概略図を示す.石英製反応管 に出発原料を充填したアルミナボートを入れ，十分に

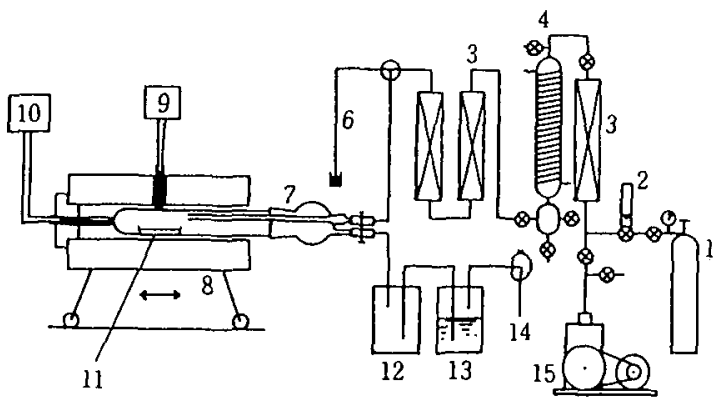

Fig. 1 Schematic diagram of reaction apparatus for making of fine magnetic powders by the Thermite method.

(1) : Cylinder (Ar), (2) : Flowmeter, (3) : $\mathrm{CaCl}_{2}$ tube, (4) : Activated $\mathrm{Cu},(5):$ Zeolite tube, (6) : $\mathrm{Hg}$ Manometer, (7) : Reaction tube, (8) : Electric furnace, (9) : Thermometer, (10) : Temp. controller, (11) : Sample and reaction boat, (12) : Receiver, (13) : Scrubbing bottle , (14) : Water-jet pump , (15) : Vacuum pump
アルゴンガスで置換した．あらかじめ所定温度 $\left(400^{\circ} \mathrm{C}\right.$ $\sim 800^{\circ} \mathrm{C}$ ) に加熱した横型電気炻中一石英製反応管を入 れ，アルゴンガス流通 $\left(200 \mathrm{~cm}^{3} / \mathrm{min}\right)$ 下で1〜3時間加熱 した後，石英製反応管を水で急冷した。温度の測定は クロメルーアルメル熱電対で行い，PID型温度コントロ 一ラにより土 $5^{\circ} \mathrm{C}$ 範囲で制御した。

各加熱条件で生成した生成物中の結晶相の生成量は 粉末法X線回折 (XRD) 装置を用い，金属ヶイ菜を内部標 準試料之してSi(111)， $\mathrm{Zn}_{\mathrm{x}} \mathrm{Fe}_{3-\mathrm{x}} \mathrm{O}_{4}$ (311)， $\mathrm{Fe} 0(200)$, Zno (100) および $\alpha-\mathrm{Fe}(110)$ 面の回折ピーク強度值をそ れぞれ求め.Si(111)面の回折ピーク強度を基準にした 相対強度值から算出した。合成した亜鈶鉄フェライト 粉末の形態，粒子径および分散状態の観察には走查型 電子顕微鏡(SEM) 用いた。また，磁気的性質は室温で の振動試料型磁力計 (VSM)により湘定した。

\section{3 実験結果およひ検討}

図2はX線強度比から求めた各化合物の存在量の焼成 温度依存性を示す。

$$
4 \mathrm{Fe}_{2} \mathrm{O}_{3}+3 \mathrm{Zn} \rightarrow 3 \mathrm{ZnFe}_{2} \mathrm{O}_{4}+2 \mathrm{Fe}
$$

なる反応を想定して $\mathrm{Zn} と \mathrm{Fe}_{2} \mathrm{O}_{3}$ とのモル比を0.75に一

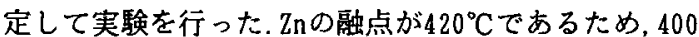

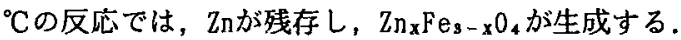
しかし、Feはごく少量しか生成しない，450ำ上の反

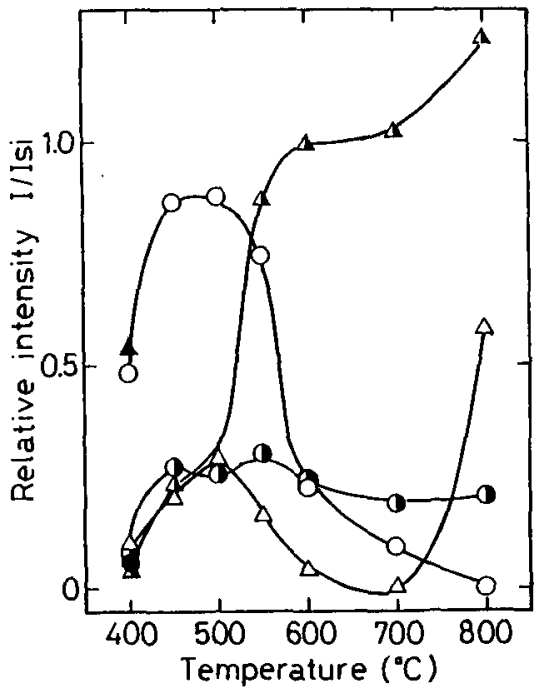

Fig. 2 Relative $\mathrm{X}$-ray diffraction intensity of products as a function of heating temperature ranging 400 to $800^{\circ} \mathrm{C}$ for $1 \mathrm{hr}$ in argon gas and $\mathrm{Zn} / \alpha-\mathrm{Fe}_{2} \mathrm{O}_{3}$ molar ratio $=0.75$.

$\mathrm{O}: \mathrm{Zn}_{\mathrm{X}} \mathrm{Fe}_{3-\mathrm{x}} \mathrm{O}_{4}$ (311), $\mathrm{OnO}(100), \mathrm{Zn}(100)$, $\triangle: \alpha-\mathrm{Fe}(110), \Delta: \mathrm{FeO}(200), \Delta: \alpha-\mathrm{Fe}_{2} \mathrm{O}_{3}(104)$ 
応ではZnおよび $\mathrm{Fe}_{2} \mathrm{O}_{3}$ は存在せず, 両者が反応している. $450^{\circ} \mathrm{C} \sim 500^{\circ} \mathrm{C}$ で焼成すると多量の $\mathrm{n}_{\mathrm{x}} \mathrm{Fe}_{3}-\mathrm{x} \mathrm{O}_{4}$ とともに $\mathrm{Fe}$ す生成する. $550^{\circ} \mathrm{C} \sim 700^{\circ} \mathrm{C}$ までの焼成温度ではスピ ネル型酸化物およびFeがそれぞれ分解し, $\mathrm{Fe} 0$ の生成量

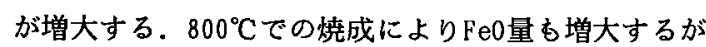
$\mathrm{Fe}$ 生成量が著しく增大する.

図了は生成物の䂭化の焼成温度依存性を示す.参考の ために強磁性を示す $\mathrm{Zn}_{\mathrm{x}} \mathrm{Fe}_{3-\mathrm{x}} \mathrm{O}_{4}$ およびFeの生成量む示 す. $450^{\circ} \mathrm{C} \sim 500^{\circ} \mathrm{C}$ で焼成した試料の磁化值（回）は50

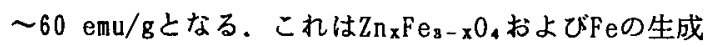
量の增大上対応している.2つの強磁性体が存在するの に磁化値が大きくないのは不純物が混在するためであ る，不純物を完全に取り除く事が困難であるため，現 状では強磁性体の正味の磁化値は評価できない。

図4は磁性酸化物の格子定数の焼成温度依存性を示す。 $400{ }^{\circ} \mathrm{C} 反$ 応で生成したスピネル型フェライトはその 格子定数が8. $396 \AA$ であり， $\mathrm{Fe}_{3} \mathrm{O}_{4}$ の格子定数, $8.39 \AA$ " にほぼ等しい，反応温度が高くなるにしたがい格子定

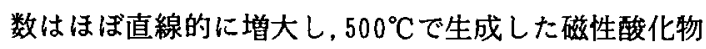
の格子定数は8.406 凡になる. $\mathrm{ZnFe}_{2} \mathrm{O}_{4}$ の格子定数が $8.44 \AA^{4)}$ であることおよび Vegardの経験則が成り立 つと仮定すると，図に示した格子定数の增大は $\mathrm{Fe}_{3} \mathrm{O}_{4}$ の 中にZnイオンが反応温度の上昇とともに固溶すること を示唆する.すなわち， $\mathrm{Zn}$ の這元力によって $\alpha-\mathrm{Fe}_{2} \mathrm{O}_{\mathrm{s}}$

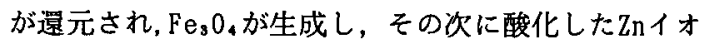
ンがスピネル構造中に固溶すると考えられる。

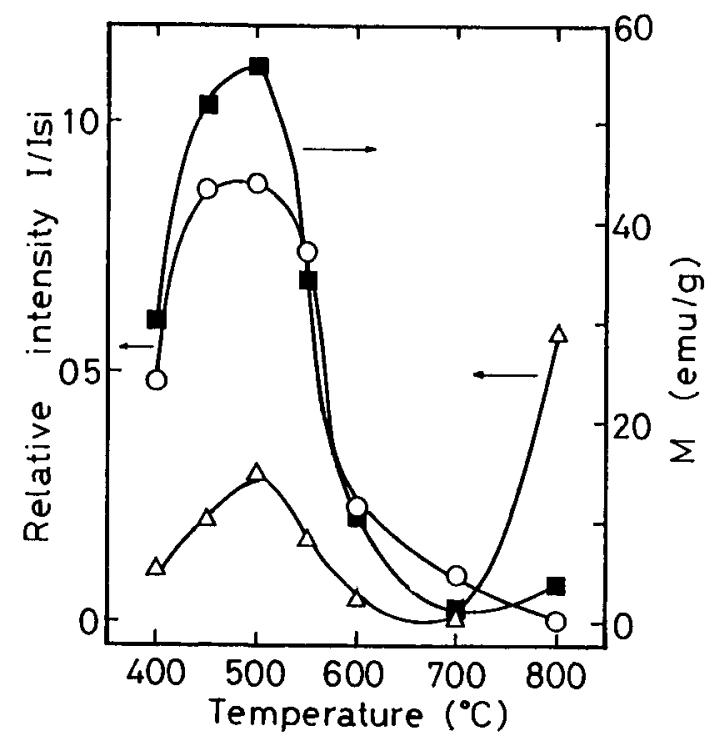

Fig. 3 Magnetization and relative intensity of products as a function of heating temperature.

口 : magnetization, $\bigcirc: \mathrm{Zn}_{\mathrm{X}} \mathrm{Fe}_{3-\mathrm{x}} \mathrm{O}_{4}, \triangle: \mathrm{Fe}(110)$
図5は $\mathrm{Zn} / \alpha-\mathrm{Fe}_{2} \mathrm{O}_{3}$ モル比に対する相対的な各生成相 を示す.すべての試料はアルゴンガス流通下, $10^{\circ} \mathrm{C} / \mathrm{min}$ の昇温温度で $500^{\circ} \mathrm{C}, 1$ 時間加熱した後急冷した. 各生 成相は $\mathrm{Zn} / \alpha-\mathrm{Fe}_{2} \mathrm{O}_{3}$ モル比により著しく変化する。すな わち, $\mathrm{Zn} / \alpha-\mathrm{Fe}_{2} \mathrm{O}_{3}$ モル比が1以下では $\mathrm{Zn}_{\mathrm{x}} \mathrm{Fe}_{8-\mathrm{x}} \mathrm{O}_{4}$ の生 成量が多く、Feの生成量は少ない，特にモル比が0.3〜 0.5 範囲では $\mathrm{Zn}_{\mathrm{x}} \mathrm{Fe}_{3-\mathrm{x}} \mathrm{O}_{4}$ が優先的に生成する. 固溶し ていないFe0およびZn0の酸化物む存在する.しかしZn $/ \alpha-\mathrm{Fe}_{2} \mathrm{O}_{3}$ が1以上ではスピネル相は還元され分解し，

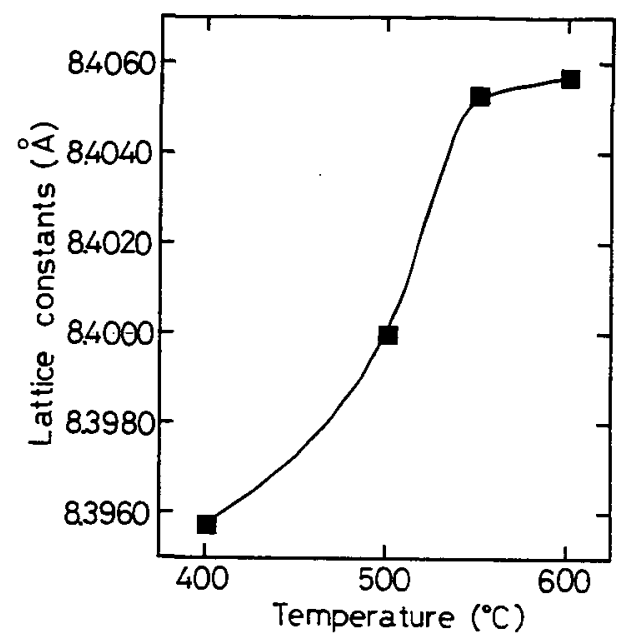

Fig. 4 Dependence of lattice constants on heating temperature ranging 400 to $600^{\circ} \mathrm{C}$ for spinel-type oxides.

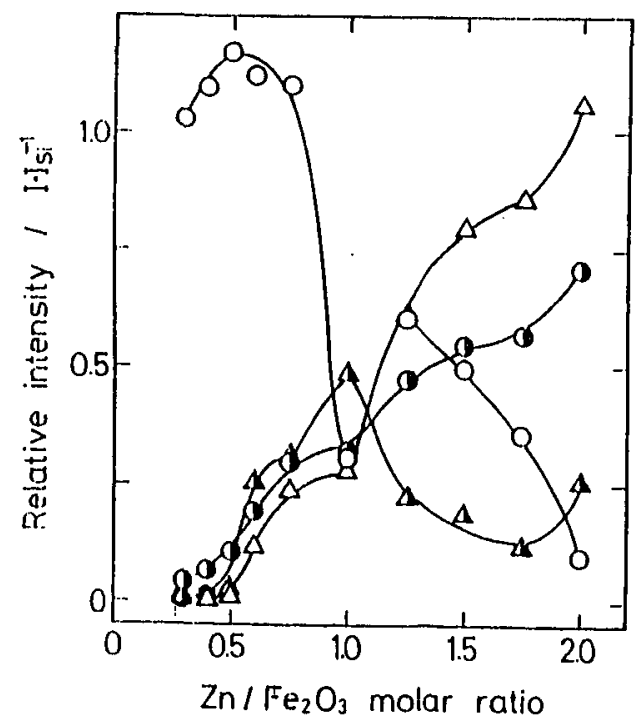

Fig. 5 Relative $\mathrm{X}$-ray diffraction intensity of products as a function of $\mathrm{Zn} / \alpha-\mathrm{Fe}_{2} \mathrm{O}_{3}$ molar ratio. $\mathrm{O}: \mathrm{Zn}_{\mathrm{X}} \mathrm{Fe}_{3-\mathrm{x}} \mathrm{O}_{4}$ (311), $\mathrm{ZnO}(100)$, $\mathrm{O}: \mathrm{Zn} \mathrm{(100),}$ $\triangle:$ Fe (110), $\Delta: \mathrm{FeO}(200), \Delta: \mathrm{Fe}_{2} \mathrm{O}_{3}$ (104) 


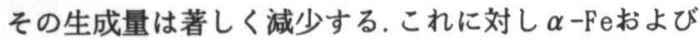
$\mathrm{Zn} 0$ の生成量が増大する. 以上のことから， $\alpha-\mathrm{Fe}_{2} \mathrm{O}_{3}$ は $\mathrm{Zn}$ により, まず $\mathrm{Fe}_{3} \mathrm{O}_{4}$ に還元され, $\mathrm{Zn} / \alpha-\mathrm{Fe}_{2} \mathrm{O}_{3}$ モル比 の増大, すなわち, 還元力の増大により $\alpha-\mathrm{Fe}_{2} \mathrm{O}_{3}$ の還 元が促進され, $\mathrm{Zn}_{\mathrm{x}} \mathrm{Fe}_{3-\mathrm{x}} \mathrm{O}_{4}$ の他に $\alpha-\mathrm{Fe}$ あ生成した.

図6 磁化値の $\mathrm{Zn} / \alpha-\mathrm{Fe}_{2} \mathrm{O}_{3}$ モル比依存性を示す. $\mathrm{Zn}$ $/ \alpha-\mathrm{Fe}_{2} \mathrm{O}_{3}$ モル比0.3〜0.5において磁化值が大きく、モ ル比が0.35の時に $85 \mathrm{emu} / \mathrm{g}$ の磁化値を示す. また保磁

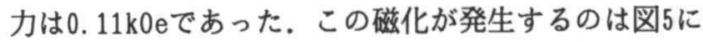
示したように主に $\mathrm{Zn}_{\mathrm{x}} \mathrm{Fe}_{3}-\mathrm{x} 0_{4}$ に因る. $\mathrm{Zn} / \alpha-\mathrm{Fe}_{2} \mathrm{O}_{3}$ モル 比が1以上になると磁化值の大きなFeの生成により磁 化値が増大するはずであるが, 非磁性物の混在により， 増大しない，非磁性物が生成せず, $\mathrm{Fe}$ と $\mathrm{Zn}_{\mathrm{x}} \mathrm{Fe}_{3}-\mathrm{x} \mathrm{O}_{4}$ が 生成するように作製条件を検討するのが今後の課題で ある.

図7は得られた微粒子粉末のSEM写真を示す. 粒子径 は0.3 0.6 $\mu \mathrm{m}$ で比較的球形状で均一性がよい.この

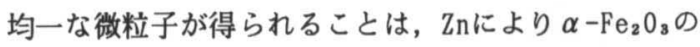
酸素が奪われるときに $\alpha-\mathrm{Fe}_{2} \mathrm{O}_{3}$ 粒子が微細化されたこ とによる.このテルミット法は均一な微粒子を得る上 で優れた方法である.

\section{4 まとめ}

テルミット法を用いて強磁性を示す $\mathrm{Fe}$ および $\mathrm{Zn} \mathrm{n}$ $\mathrm{Fe}_{3}-\mathrm{x} 0_{4}$ 混合粉末を作製した. すなわち, $\mathrm{Zn} / \alpha-\mathrm{Fe}_{2} \mathrm{O}_{3}$ の

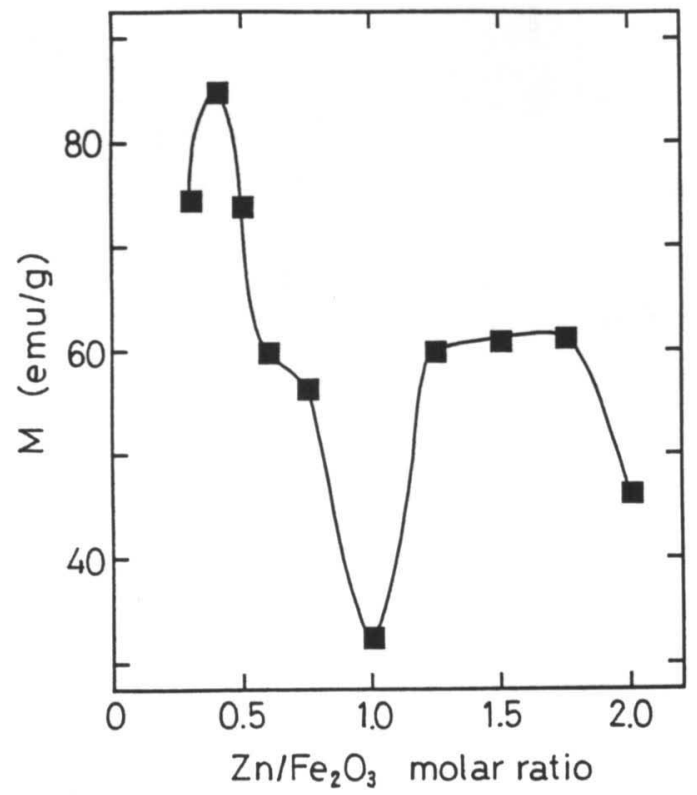

Fig. 6 Dependence of magnetization on $\mathrm{Zn} / \alpha-$ $\mathrm{Fe}_{2} \mathrm{O}_{3}$ molar ratio.
モル比が0.3〜2.0の原料を十分に混合し, 石英製反応 管に入れ十分にアルゴンガスで置換した. アルゴンガ ス流通下で $400^{\circ} \mathrm{C} \sim 800^{\circ} \mathrm{C} て ゙ 1 〜 3$ 時間焼成後急冷した. これらの試料の生成相および磁気特性を調べた. $450^{\circ} \mathrm{C}$ $\sim 500^{\circ} \mathrm{C}$ で焼成すると, 多量の $\mathrm{Zn}_{\mathrm{x}} \mathrm{Fe}_{3-\mathrm{x}} \mathrm{O}_{4}$ が生成した。 $550^{\circ} \mathrm{C} \sim 700^{\circ} \mathrm{C}$ で焼成するとスピネル型酸化物および $\mathrm{Fe}$ が共に分解し, $\mathrm{Fe} 0$ の生成量が増大した. $800^{\circ} \mathrm{C}$ 以上の 焼成ではFeの生成量が増大した. $450^{\circ} \mathrm{C} \sim 500^{\circ} \mathrm{C}$ 焼成し た試料の磁化値は $50 \sim 60 \mathrm{emu} / \mathrm{g}$ であった.

$\mathrm{Zn} / \alpha-\mathrm{Fe}_{2} \mathrm{O}_{3}$ モル比が1以下では $\mathrm{Zn}_{\mathrm{x}} \mathrm{Fe}_{3}-\mathrm{x} \mathrm{O}_{4}$ 相が主に 生成した. モル比が0.35の試料の磁化值は $85 \mathrm{emu} / \mathrm{g}$, 保磁力は $0.11 \mathrm{k} 0 \mathrm{e}$ であった. モル比が1以上ではスピネ ル相は分解しその生成量は著しく減少した. しかしFe の生成量が増大した。

作製した粉末は粒子径が0. $3 \sim 0.6 \mu \mathrm{m}$ で比較的球形状 をしており均一であった. 非磁性酸化物の生成量を減 少することが今後の課題である.

\section{文 献}

1) 杉本光男, 平塚信之, 藤田実：日本応用磁気学会誌, 2 (1980) 89.

2) 茂呂英治, 宮内泰治, 森輝夫: 粉体粉末冶金協会平 成3年度秋季大会講演概要集（1991） 52.

3）平塚信之, 福井重充, 藤田実, 杉本光男: 粉体および 粉末冶金, 3 (1991) 335.

4) 近角聡信: "強磁性体の物理（上）", 裳華房, (1978) 222 .

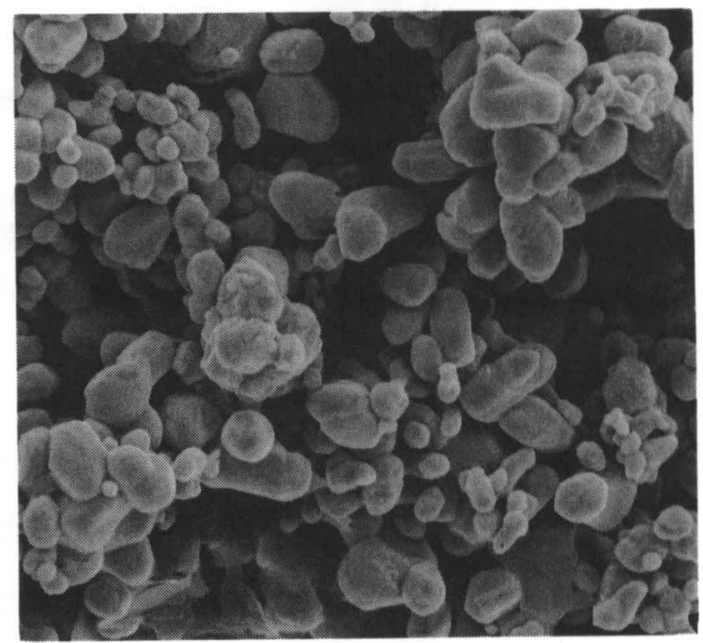

Fig. 7 SEM photograph of fine powders synthesized at $500^{\circ} \mathrm{C}$ for $3 \mathrm{hrs}$ in argon gas. 